\title{
Challenged and satisfied: The role of organisational ownership and employee involvement
}

\begin{abstract}
This study aims to offer a more fine-grained approach to our understanding of the relationship between job stress and job satisfaction. Building on organisational theory and Karasek’s (1979) Job Demand-Control model, we investigated an important institutional characteristic organisational ownership - as an additional moderator to influence the interactive effects of job demands and control upon job satisfaction. Using data collected from 1,838 Chinese retail sector employees China, we found that this three-way interaction was strongest for employees working in foreign-invested firms, who experienced higher employee involvement at work and perceived a high level of challenge-related stress. The relationship was weakest for employees in state-owned enterprises who reported low levels of both employee involvement and challenge-related stress. Our study constitutes an early attempt to assess the impact of institutional characteristics such as ownership on aspects of human resources management, and highlights the need for further research to recognize the importance of such characteristics as contextual factors that influence the effect of organisational practices and the work environment upon individual work-related outcomes. The paper's concluding sections elaborate on the contributions our research makes both to theory as well as to the practicalities faced by human resource managers in contexts such as China.
\end{abstract}

Keywords: challenge-related stressors; Job Demand-Control model; organisational ownership; job satisfaction; employee involvement; China 


\section{Introduction}

Considerable attention has been devoted to the study of workplace stress and job satisfaction; topics of major concern to both human resource (HR) researchers and practitioners. Karasek's (1979) seminal Job Demand-Control (JDC) model has served as a key theoretical basis to explain the effects that work demands have on job satisfaction (Häusser, Mojzisch, Niesel, \& Schulz-Hardt, 2010; Podsakoff, LePine, \& LePine, 2007). In the JDC model, work demands are viewed as stressors, while control is seen as a moderator of stress. The model hypothesises that jobs characterised by high demands and low control threaten individuals' mental and physical well-being, while those that combine high demands with high control positively affect these dimensions (Karasek, 1979). Furthermore, Karasek maintains that the interaction between demands and control should be more predictive than the additive effects of high demands and low control upon employees’ well-being, including job satisfaction.

Yet, while empirical studies have provided consistent support to the direct effects of job demands and control upon job satisfaction (for example, see meta-analyses by LePine, Podsakoff, \& LePine, 2005; Podsakoff et al., 2007), the suggested interactive effect of job demands and control upon job satisfaction (Karasek, 1979), has received limited and even contradictory support (Häusser et al., 2010). While some research supports the buffering hypothesis, which suggests that high levels of job control or social support can buffer against the negative effect of a demanding job (Brown, Pitt-Catsouphes, McNamara, \& Besen, 2014; De Witte, Verhofstadt and Omey 2007), this conclusion is far from unanimous. Additionally, scholars highlight the importance of contextual specificity given that the origins of work stress are primarily based on the structural and organisational aspects of the work environment rather than personality variables (Karasek, 1979). Thus, in addition to perceptual measures of the environment (i.e., job demands and control), it is argued that additional organisation contextual factors should be considered to further influence the proposed effect of job demands and control 
upon job satisfaction (Arnold, Flaherty, Voss, \& Mowen, 2009; McClenahan, Giles, \& Mallett, 2007; Sparks \& Cooper, 1999).

Addressing these knowledge gaps, in this study we first examine the interactive effect of job demands and control upon job satisfaction, we then seek to understand further organisational factors influence on the job demands-control-job satisfaction relationship. In particular, we explore the moderating role of organisational ownership in this relationship. We use organisational ownership to specify institutional conditions. In other words, organisational ownership is used as a proxy for differences in terms of competitive environment, organisational culture and management practices, because it has been well documented to influence management practices (e.g., for a review of China-based HRM-performance studies, see Kim, Wright, \& Su, 2010; Peng, Tan, \& Tong, 2004). Our focus on organisational ownership responds to recent calls (e.g. Brown et al., 2014; Häusser et al., 2010) to investigate the impact of contextual factors on workplace stress and its related outcomes. More specifically, we focus on two major organisational ownership types in China (Xu, Lu, \& Gu, 2014): stateowned enterprises (SOEs) and foreign-invested enterprises (FIEs).

Theoretically, this research offers a more comprehensive view to understand the association between job demands, job control, and job satisfaction. By examining the moderating role of organisational ownership from an institutional view, we extend the extant JDC literature by further unpacking the importance of contextual specificity in influencing the job demands-control-job satisfaction interaction. We argue that the interactive effect of job demands and control upon job satisfaction will be further influenced by organisational ownership type. Empirically, given the limited and often equivocal support for the two-way interactive effects between demands and control upon job satisfaction, our research provides further empirical evidence to help understand this understudied relationship (Brown et al., 2014; Häusser et al., 2010). Another empirical contribution of our study is our focus on the retail 
sector industry context. We investigate the three-way interactive relationship among retail employees; this focus is important given the often stressful nature of the retail work environment (Broadbridge, 2002; Bozkurt \& Grugulis, 2011). This study will enable us to confirm whether existing stress-job satisfaction findings, derived largely from Western contexts, are replicated in a substantively different institutional and cultural environment.

\section{Theoretical background}

\section{The JDC model and the challenge-hindrance stressors framework}

In research on job stress, the JDC model is an influential approach that underscores the importance of control. Karasek (1979) defines job demands as psychological stressors present in the work environment (e.g. long working hours). Job control denotes the worker's ability to control his/her own activities (Karasek, 1979). The model's central tenet is that a high level of job control protects employees from potentially harmful effects of demanding jobs. When both demands and control are high, employees are likely to perceive the situation as "challenging" (Boswell et al., 2004), thus a high demand-high control situation should result in desirable outcomes such as increased satisfaction and motivation. In contrast, when an individual experiences high pressure but low control, the situation is proposed to be particularly undesirable. Building upon this JDC perspective, Cavanaugh, Boswell, Roehling and Boudreau (2000), distinguish between two types of stressor: challenge and hindrance-related stressors. In the challenge-hindrance stressor framework (Cavanaugh et al., 2000), challenge-related stressors refer to job demands that employees perceive as rewarding work experiences which create opportunities for personal growth (e.g. time urgency, job responsibility, and job complexity), whereas hindrance-related stressors refer to job demands viewed as obstacles to personal growth or that hinder the achievement of valued goals (e.g. situational constraints, organisational politics, role ambiguity, and role conflict). 
While the two aforementioned sets of literature cover similar territory, their conceptualisation of stress differs. While the JDC model mainly examines effects of potential hindrance-related stressors, the challenge-hindrance stressor framework considers stress from a broader perspective and allows the possibility that stress can have a positive impact on individuals (LePine et al., 2005; Podsakoff et al., 2007). Researchers adopting the JDC model consistently report a strong negative effect between stressors (mostly viewed as obstacles) and job satisfaction (LePine et al., 2005; Podsakoff et al., 2007). Meanwhile, studies utilising the challenge-hindrance stressor framework report differential relationships between them and various outcomes. For instance, hindrance-related stressors tend to relate negatively to outcomes such as job satisfaction (Podsakoff et al., 2007), performance (Pearsall, Ellis, \& Stein, 2009), and retention (Podsakoff et al., 2007), whereas challenge-related stressors associate more unfavorably to these outcomes. However, evidence for the relationship between challenge type stressors and job satisfaction is inconclusive. While some studies report a positive effect (Beehr, Glaser, Canali, \& Wallwey, 2001; Boswell, Olson-Buchanan, \& LePine, 2004; LePine et al., 2005; Podsakoff et al., 2007; Webster, Beehr, \& Christiansen, 2010), others find the relationship to be negative or insignificant (e.g., de Lange, Taris, Kompier, Houtman, \& Bongers, 2004; Doest \& Jonge, 2006). Thus, we believe it is important to provide further evidence of the additive and interactive effects of challenge stress upon job satisfaction. Consequently, our study focuses on challenge-related stressors such as pressure to complete tasks and time urgency.

Consistent with the empirically testable hypotheses proposed by the JDC framework, we posit a model in which increased job satisfaction can result from both additive and interactive effects of challenge-related stressors and job control. In particular, following Cavanaugh et al.'s (2000), challenge-hindrance stress framework, we focus on challenge-related stressors, including pressure to complete tasks and time urgency. Our decision to focus on a specific type 
of stress is guided by the conclusion that challenge and hindrance-related stressors exert distinctive and differential impacts upon work-related outcomes, and that challenge-related stressors have received mixed empirical support (LePine et al., 2005; Podsakoff et al., 2007). Furthermore, we utilise employee involvement as a form of job control. As Boswell et al. (2004, p. 170) remark, job control plays "a particularly important role for challenge stress such that challenging experiences may only be desirable to the extent that employees perceive job control”.

\section{Organisational ownership and the retail industry}

With few exceptions (e.g., Lu, Siu, Au, \& Leung, 2009; Widerszal-Bazyl, Cooper, Sparks, \& Spector, 2000), studies on job stress neglect the potential role of organisational ownership type. This is surprising given well-documented institutional differences between organisational settings (Xu et al., 2014). We argue that work stress does not occur in a vacuum, and that differences in organisational ownership, practices and cultures can create work dynamics that affect the stressors to which an individual is exposed (Kim et al., 2010; Lu et al., 2009). Such dissimilar work dynamics might correspondingly impact differently upon employees’ perceived stress and psychological outcomes (Sparks \& Cooper, 1999).

Our use of ownership as a proxy for differences in competitive environment, organisational culture and management practices is guided by both theoretical and empirical reasoning. Organisational theorists suggest that "ownership is the most important determinant of the organisational form for transition economies such as China” (Xu et al., 2014, p. 525). Kim et al. (2010) argue that ownership type has profound implications, especially in emerging economies, because companies of differing ownership present markedly different sets of institutional and organisational arrangements. Empirically, studies highlight correspondingly significant differences in terms of HRM, organisational culture and individual attitudes and 
behaviours between different ownerships (e.g. Braun \& Warner, 2002; Gamble, 2006; Gamble \& Huang, 2008; Jin, Fosh, \& Chen, 2012; Zhu, Cooper, De Cieri, \& Dowling, 2005).

Our decision to focus on two ownership types, SOEs and FIEs, reflects their distinctive and differing characteristics (Peng, 2003; Peng et al., 2004; Xu et al., 2014). SOEs tend to be large and complex and have access to nationally controlled economic resources, such as capital (Wei \& Lau, 2008). They are subject to more governmental influences, less market-oriented, and often "managed by older, conservative managers" (Peng et al., 2004, p. 1111). Political interference and SOEs' bureaucratic structure reduces their flexibility in managing people. In contrast, FIEs generally face fewer institutional constraints, adopt a more market-oriented approach to managing their employees and enjoy greater autonomy and flexibility in employment than SOEs (Law, Tse, \& Zhou, 2003; Ngo, Lau, \& Foley, 2008; Wei \& Lau, 2008). Although China's SOEs have gradually adopted more Western style HRM practices, they are still less market-oriented than FIEs (Zhu et al., 2005).

Given such well documented differences between SOEs and FIEs, we consider it worthwhile to operationalise organisational ownership type as a contextual factor which may affect employees' stress and its associated work outcomes (Kim et al., 2010; Peng et al., 2004; Wang, 2004). A few studies indicate that FIE employees feel more involved in decision making, more satisfied with their jobs and perceive them to be more demanding than those experienced by their SOE counterparts (Gamble, 2003, 2006; Huang \& Gamble, 2011). For instance, Gamble (2003, 2006) tracked the organisational practices and employees’ experience of them in a British multinational retailer in China over several years. This FIE had relatively open and consultative practices, including a comparatively flat hierarchy and mechanisms whereby managers actively sought workers' opinions and were responsive to employee feedback. The FIE's employees also reported longer working hours, greater work pressure and were more likely to worry about their job outside work time than their counterparts in SOE stores. 
More generally, while evidence exists, separately, for the potential role of stress, job control and organisational ownership type as predictors of positive work outcomes such as increased job satisfaction (e.g. Lu et al., 2009), the simultaneous interaction of these predictors (job demands, control, and organisational ownership) remains unexplored. We propose that exploring organisational ownership as an additional moderator that can influence the interactive effects of job demands and control upon job satisfaction should yield a richer, more complete understanding of the relationship between stress and positive work outcomes. Through such an explorative analysis of workers in SOEs and FIEs in China, we hope to provide preliminary evidence for this theoretical consideration.

Alongside organisational contextual factors, the wider industrial context might also influence the type of stressors to which an individual is exposed. Retail industry employment is often characterised by non-standard and precarious work arrangements, low-wages, excessive work demands, intensive customer interaction and a rapidly changing work environment (Coelho, Augusto, \& Lages, 2011; Bozkurt \& Grugulis, 2011). Frontline retail employees are also often expected to engage in “emotional labour” (Grandey, 2003; Lashley, 2001), as well as continually balance the expectations of management and customers. These features contribute to a highly stressful working environment (Arnold et al., 2009). Furthermore, rising customer demands have, potentially, made jobs in the retail industry even more stressful (Broadbridge, 2002). This is particularly true in the Chinese retail sector which has transformed significantly, especially since China's accession to the World Trade Organisation in November 2001. The subsequent influx of foreign retailers substantially increased competitive pressures in its retail system (Gamble, 2010).

To date, the retail industry has largely been neglected in the literature on workplace stress, despite researchers identifying jobs in retailing as “over average” or even "very” stressful (Broadbridge, 2002; Bozkurt \& Grugulis, 2011). We help to address this gap in the literature; 
moreover, our focus on China's retail industry is particularly apposite given that, despite its economic significance, "study of China's service sector and employment relations within it remains in its infancy” (Gamble, 2010, p. 7). In view of these characteristics, a simultaneous investigation into the interaction of Chinese retail employees' stress, organisational contextual factors and desirable employee work-related outcomes is both timely and important.

\section{Hypotheses development}

\section{Challenge-related stressors and job satisfaction}

In this study, we focus on job satisfaction as a form of positive work outcome for retail employees for two main reasons. Firstly, job satisfaction is a widely used measure of positive work stress outcomes (Podsakoff et al., 2007; Vandenberghe, Panaccio, Bentein, Mignonac, \& Roussel, 2011; Webster et al., 2011). Secondly, it is particularly important in the retail industry since employee satisfaction in this sector can contribute to customer satisfaction (Heskett, Sasser, \& Schlesinger, 1997).

As noted above, while some research reports a strong negative effect between hindrance stressors and job satisfaction (LePine et al., 2005; Podsakoff et al., 2007), evidence for the relationship between challenge-related stressors and job satisfaction is less well understood. However, Podsakoff et al.'s (2007) meta-analysis of results from 183 independent samples, confirmed a positive relationship between challenge-related stressors and job satisfaction. Consistent with the latter we hypothesise the following:

Hypothesis 1: Challenge-related stressors will be positively related to job satisfaction.

\section{Employee involvement and job satisfaction}

Employee involvement or participation has become a key research theme within studies of strategic HRM (Lavelle, Gunnigle, \& McDonnell, 2010). These include practices that 
encourage involvement in decision-making and the development and exercise of problemsolving skills. Employee involvement practices have been shown to reduce job stress (Mackie, Holahan, \& Gottlieb, 2001), increase job satisfaction and organisational commitment (Boxall \& Macky, 2014; Holland, Pyman, Cooper, \& Teicher, 2011; Macky \& Boxall, 2008), and improve productivity and organisational performance (Wood, Van Veldhoven, Croon, \& de Menezes, 2012).

Employee involvement can be used as a measure of job control, since high involvement practices give workers greater control over their jobs (Boxall \& Macky, 2014; Mackie et al., 2001; Macky \& Boxall, 2008; Wood, 2008). Researchers argue that involvement practices can reduce work stress through an increased sense of personal control, less role ambiguity, increasing participation in decision-making and by providing for greater utilization of skills. Wood and de Menezes (2011, p. 1590) observe that "high involvement management may signal to the employee that they are respected and that their contribution is valued" and "individuals may also use their discretion...to reduce hindrance stressors”.

Several studies demonstrate that employees who are involved in decision-making processes tend to feel a heightened sense of ownership over their job performance because they feel personally responsible for how tasks are accomplished (Mackie et al., 2001; Wood et al., 2012). Furthermore, Warr (2007) suggests that greater employee involvement may increase the meaningfulness of work, such that individuals consider their work as a career rather than simply as a job, this in turn may increase their job satisfaction. Similarly, other research has found that involvement in decision-making processes can improve employee satisfaction (e.g. Boxall \& Macky, 2014; Cox, Zagelmeyer, \& Marchington, 2006; Holland et al., 2011; Macky \& Boxall, 2008; Wood, 2008). Hence, we hypothesise the following:

Hypothesis 2: Employee involvement will strengthen the relationship between challengerelated stressors and job satisfaction. 


\section{Joint effects of challenge-related stressors, employee involvement and ownership type}

In the Chinese context, as noted above, researchers have long reported that SOEs and FIEs differ considerably in terms of competitive environment, organisational culture and management practices. It can be anticipated that such distinctive differences between SOEs and FIEs would create correspondingly different work dynamics that may affect employees' job satisfaction. For example, studies report low levels of employee involvement in SOEs and little upward or downward communication between employees and managers (Gamble, 2003, 2006;

Lu et al., 2009). A handful of studies compare Chinese employees’ job satisfaction across different organisational ownerships. For example, Huang and Gamble (2011) found that employees in FIEs, where communication and involvement practices are generally better implemented, tended to report higher levels of job satisfaction than those in SOEs. Wang (2008) found privately-owned enterprises employees to be more satisfied and committed to their jobs than employees in SOEs. However, SOEs' greater emphasis on equality and stability might be appreciated by some workers and positively influence their job satisfaction (Zhu et al., 2005). Thus, the potential effects of organisational ownership upon employees' attitudes remain poorly understood and our study provides further empirical evidence.

Given the considerable differences in terms of managerial practices between SOEs and FIEs, we argue that to better understand the relationship between challenge-related stressors and job satisfaction, it is important to investigate employees’ job satisfaction in conjunction with the organisational contexts which might influence the outcome. This argument takes seriously Sparks and Cooper's (1999) view that, to better understand the effect of work stress, research should incorporate variables that are specific to a particular work context.

We expect interaction effects between these variables for several reasons. Firstly, an interaction between stressors and employee involvement follows the logic of the JDC model. 
Involvement in decision-making processes and information sharing might make employees feel valued and acknowledged, and more satisfied with their jobs (Warr, 2007; Wood \& de Menezes, 2011). The perception of being more valued and satisfied when high involvement management is practiced may also amplify feelings of being challenged at work. Secondly, we expect variance between different types of organisational ownership to enhance or inhibit the relationship between workplace stress and job satisfaction. Such differences might work in conjunction with employee perceived work stress to influence job satisfaction.

In light of the above, we argue that employees’ job satisfaction might be a result of additive as well as interactive effects of workplace stress, job control and organisational ownership. Alongside the interactive effects of stress and job control of the JDC model, we predict a threeway interaction of challenge-related stress, job control and ownership. We posit that employees who perceive simultaneously high levels of both challenge-related stressors and high involvement at the workplace and who work in FIEs are likely to experience greater job satisfaction. Accordingly, we hypothesise that:

Hypothesis 3: Challenge-related stressors will be more strongly associated with job satisfaction for employees who work in FIEs, and who experience higher employee involvement at work.

\section{Method}

\section{Sample and procedures}

Our sample is drawn from a survey of employees from several FIE and SOE retailers located in nine different Chinese cities. Selecting participants from a single industry aids comparability; it helps reduce the possible influence of confounding variables, such as job nature (e.g., Chiang, Birtch, \& Kwan, 2010). Questionnaires were distributed to a random cross-section of employees at twenty-two stores; 1,838 usable responses were received, an effective response rate of 86.3 per cent. Respondents comprised 53.3 per cent from SOEs and 46.7 per cent from 
FIEs. As shown in Table 1, the majority of respondents were non-managerial employees (83.2\%), aged below 28 years of age (61.6\%), female (52.8\%), and had education equivalent to senior high school or below (72\%).

\section{Insert Table 1 about here}

\section{Measures}

Specific questions and translations were discussed with Chinese colleagues to ensure their comprehensibility and applicability. Additionally, both authors are Chinese and English bilinguals, one being a native speaker. To maximise translation equivalence (Mullen, 1995), the final Chinese text was back-translated to English by a bilingual research assistant. The questionnaire is based partly upon the United Kingdom Department of Employment's Workplace Employee Relations Survey (WERS), as such it is a well-tested and robust research instrument. The scales employed have also been used in other studies using Chinese samples which demonstrate the appropriateness of these sets of measures for this context (e.g. Gamble \& Huang, 2008, 2009; Huang \& Gamble, 2011, 2015). Except where noted, survey items were measured on five-point Likert-format scales ( 1 = strongly disagree or very dissatisfied; 5 = strongly agree or very satisfied).

Challenge-related stressor: The challenge-related stressor measure consisted of three items similar to the measure of Cavanaugh et al. (2000). Participants were asked to indicate how their job made them feel. A sample item is "My job requires me to work very hard”. Coefficient alpha for this measure was .88 .

Job satisfaction: The employee job satisfaction measure consisted of six items that capture respondents' satisfaction with their pay and benefits, the sense of achievement they get from their work, the recognition received from their managers, perceived promotion opportunities and the effectiveness of performance appraisal. This scale has been employed in various studies 
(e.g. Carr \& Mellizo, 2013; Huang \& Gamble, 2011; Wood \& de Menezes, 2011). A sample item is "I am satisfied with the payment in this company". Coefficient alpha for this measure was .72.

Employee involvement: The employee involvement scale consists of five items which measure whether managers consult employees in five separate aspects: future business planning, job arrangement, changes in work procedures, remuneration policies, and health and safety issues. The scale has been used by previous studies both in the Chinese and non-Chinese context (e.g., Huang \& Gamble, 2011; Wood, 2008). A sample item is "Managers consult employees about job arrangement”. Coefficient alpha for this measure was .72.

Organisational ownership: Organisations were grouped and dummy coded into two categories: state-owned (SOEs $=0)$, and foreign-owned $($ FIEs $=1)$.

Control variables: The following variables were included as controls: gender (female $=1$, male $=0$ ), age (less than 22 years old, 22-27 years old, 28-33 years old, 34-45 years old, and 46 and above), job level (non-managerial staff $=0$, managerial staff $=1$ ), tenure (less than 1 year, 1-2 years, 3-4 years, and 5 years and above), and education (high school and below, college, and university and above).

\section{Analyses}

We used Mplus 6.12 to assess the measurement model (Muthén \& Muthén, 2007). We examined our hypothesised model, which comprised the challenge-related stressors, job satisfaction, employee involvement, and organisational ownership measures. All factors were allowed to correlate, except for the items error terms. We assessed model fit by assessing TLI and CFI (values $>0.90$ are acceptable, $>0.95$ excellent), RMSEA $(<0.08$ is acceptable, $<0.05$ is excellent) and SRMR (<0.08 is acceptable) (see Bentler, 1990; Hu \& Bentler, 1999). 
The measurement model was acceptable $(\Delta \chi 2=13.09$; $\mathrm{CFI}=0.96 ; \mathrm{TLI}=0.95 ; \mathrm{RMSEA}=$ 0.07; SRMR $=0.06$ ). All estimates in the model were significant at $p<.01$. To check their distinctiveness, we tested a model in which all variables were loaded onto a single factor and other specifications were the same as the hypothesised model. The model fit was substantially worse than the hypothesised model $(\Delta \chi 2=264.60, \mathrm{CFI}=0.64 ; \mathrm{TLI}=0.57$; $\mathrm{RMSEA}=0.23$; SRMR = 0.15). Thus, we concluded that the hypothesised four-factor model was sufficiently distinctive.

We used two post hoc tests to determine the extent of common method bias (CMB) in the data. First, we employed Harman’s one-factor test (Podsakoff, MacKenzie, \& Podsakoff, 2012). The unrotated principal components analysis solution resulted in nine factors with eigenvalues greater then 1.0, accounting for 52.33\% of the variance. No general factor emerged, whereas the first factor explains only $28.86 \%$ of the variance. We then conducted a one-factor CFA with all first-order factors included and restricted to load on a single factor. The results obtained from this analysis indicated a poor fit: $\mathrm{x}^{2}=8767.88 \mathrm{df}=65 ; \mathrm{p}<.001$; CFI $=.64$, TLI $=.56$, RMSEA $=.25$, and SRMR $=.16$. Although Harman's single-factor test has limitations, these results indicate that CMB does not pose a serious problem in our investigation. Second, we also tested for CMB using the marker-variable approach proposed by Lindell and Whitney (2001). This is a partial correlation procedure designed to control for method bias. Because the questionnaire was not designed a priori to include a marker variable, we used the approach in a post hoc fashion as suggested by Lindell and Whitney (2001). Accordingly, we used the smallest positive correlation ( $r=.03$, between tenure and employee involvement) as a marker variable, for which we calculated the focal correlations between challenge-related stressors, employee involvement, organisational ownership and job satisfaction. We calculated the CMBadjusted correlation for all focal constructs and its t-statistic using Lindell and Whitney's (2001) formulas. This procedure made no difference to the statistical significance of any correlation. 
Taken together, these two sets of analyses confirm that, although CMB cannot be completely ruled out, it is not a major threat to the interpretation of our findings. This finding is consistent with other research on CMB which has concluded that while method bias may be present, it may not always significantly affect results or conclusions (e.g., Conger, Kanungo, \& Menon, 2000; Katsikea, Theodosiou, \& Morgan, 2014).

\section{Results}

We tested the hypothesised relationships using hierarchical moderated regression analysis. For this analysis, challenge-related stressor was used as an independent variable, and employee involvement and ownership type used as moderator variables. Interaction terms were then included in the model. The variables were mean-centred to reduce multicollinearity and then multiplied together (Aiken \& West, 1991). Interaction effects were inspected by plotting regression slopes of the two subgroups - at one standard deviation above the mean, and at one standard deviation below the mean.

Table 2 provides means, standard deviations, and correlations among all the study variables. As indicated, challenge-related stressor is positively correlated with employee involvement $(\mathrm{r}=.23, \mathrm{p}<.01)$, job satisfaction $(\mathrm{r}=.21, \mathrm{p}<.01)$, and working in FIEs $(\mathrm{r}=.06$, $\mathrm{p}<.01)$. One-way ANOVAs were conducted to compare corresponding means for the two organisational ownership samples by showing $\mathrm{F}$ values. As shown in Table 3, the level of perceived challenge-related stressors was higher in FIEs than in SOEs (Mean FIEs Vs. SOEs = 3.73 vs. 3.65). Employees in FIEs also reported higher levels of both involvement (Mean FIEs Vs. SOEs $=3.18$ vs. 3.13 ) and job satisfaction (Mean FIEs Vs. SOEs $=2.70$ vs. 2.48 ) than those in SOEs. These initial results are consistent with our hypothesised relationships.

\section{Insert Tables 2 \& 3 about here}


Hierarchical linear regressions were used to test all three hypotheses (See Table 4). The predictors were entered into the regression in the following four steps: (1) in Model 1, we included only the control variables: gender, age, job-level, education and job tenure; (2) Model 2 tests the main effects of challenge-related stressors, employee involvement and ownership type upon job satisfaction; (3) Model 3 adds the two-way interactions between challengerelated stressors and employee involvement; and (4) Model 4 adds the proposed three-way interaction (challenge-related stressors x employee involvement x ownership type).

\section{Insert Table 4 about here}

Further to the positive correlation between challenge-related stressors and job satisfaction $(r=.21, \mathrm{p}<.01)$ reported in Table 2 , the results presented in Table 4 indicate that the regression coefficient for challenge-related stressors in Model 2 was highly significant $(\beta=.09, p<.001)$. It remained significant even after the addition of interaction terms in Models 3 and 4. These results offer support for Hypothesis 1, which predicts that challenge-related stressors are positively related to job satisfaction. We then tested the moderating effects of employee involvement upon the relationship between challenge-related stressors and job satisfaction as proposed in Hypothesis 2. The regression coefficient for employee involvement in Model 2 was significant $(\beta=.26, p<.001)$ indicating a direct impact of employee involvement upon job satisfaction. The effect of employee involvement remained significant after including all the interaction terms into Models 3 and 4. This means that employee involvement acts as an independent antecedent as well as a moderator of job satisfaction. However, with regard to the interaction effect of employee involvement, Model 3 shows that the addition of the two-way interaction (challenge-related stressors x employee involvement) did not significantly increase the overall variance explained. The interaction term of challenge-related stressors and employee 
involvement was not significantly related to job satisfaction $(\beta=-.01$, n.s.). Thus, the results did not support Hypothesis 2.

Hypothesis 3 specified that employees with a stronger sense of challenge-related stress experiencing high involvement at work, and working in FIEs, were likely to report higher levels of job satisfaction. The results presented in Table 4 reveal that the addition of the three-way interaction (challenge-related stressors x employee involvement x ownership type) significantly increases the overall variance explained by .01 $(F=3.22, p<.05)$. This increment suggests that the model including the three-way interaction is slightly superior to a model without this integration. The $\mathrm{R}^{2}$ increases from .06 in Model 1 to .21 in Model 4, which is equivalent to an increase of 15 per cent. The nature of the interaction was probed following procedures recommended by Aiken and West (1991). The results are plotted in Figure 1. The level of satisfaction is highest for those employees who work in FIEs, and who also reported high levels of both challenge-related stressors and employee involvement. To investigate this further, we calculated the unbiased beta weights for each slope along with the t-test for each pairwise comparison (Dawson \& Richter, 2006). The results are reported in Table 5, which shows that slope 1, representing employees who perceive high levels of both employee involvement and challenge-related stressors and who currently work in FIEs, is significantly different from the other three slopes. This finding lends support to Hypothesis 3.

\section{Insert Table 5 \& Figure 1 about here}

\section{Discussion}

Our results confirm the general expectation that challenge-related stressors lead directly to increased job satisfaction. This is consistent with prior studies that use time urgency and workload as measures of challenge-related stressors (Beehr et al., 2001; Boswell et al., 2004; 
Podsakoff et al., 2007; Webster et al., 2010). However, in terms of interactive effect, while both employee involvement and challenge-related stressors were found to strongly and positively influence perceptions of job satisfaction, the hypothesised two-way interaction (Hypothesis 2)

did not further strengthen the positive relationship between perceived challenge-related stressors and job satisfaction. Furthermore, we tested whether organisational ownership could be a further influential factor in strengthening or weakening the interactive effect of stress and control on job satisfaction relationship (Hypothesis 3). As we anticipated, the three-way interaction (challenge-related stressors x employee involvement x ownership) led to an increase in employee job satisfaction, although the magnitude is small. These results have important theoretical and practical implications that we discuss below.

\section{Theoretical and empirical implications}

With regard to the JDC literature, our investigation offers a key theoretical contribution by identifying organisational ownership as a potential moderator which shapes how individuals perceive and react to workplace stress. Brown et al. (2014) and Häusser et al. (2010) recommended that workplace stress studies need to take a contingent approach and identity contextual factors that can directly or indirectly shape the relationships between workplace stress and its related outcomes. Recognising organisational ownership as an important institutional factor, our three-way interaction results justify calls (e.g. Arnold et al., 2009; Lu et al., 2009; Sparks \& Cooper, 1999) to develop more situation-specific approaches to understand the relationship between job stress and its related outcomes. We anticipated that this relationship would be strongest for employees who work for FIEs, and who experience higher levels of involvement in work-related matters (Hypothesis 3).

In line with our expectations, we found significant differences between FIEs and SOEs for all our key constructs (employee involvement, challenge-related stressors, job satisfaction). In 
general, FIEs employees reported higher levels of challenge-related stressors and job involvement, and felt significantly more satisfied with their jobs than employees working in SOEs. As we anticipated, the three-way interaction (challenge-related stressors $\mathrm{x}$ employee involvement x ownership) led to a modest increase in satisfaction between employees with low involvement and high challenge-related stressors in FIEs compared with SOEs. However, in FIEs with high involvement and higher challenge stress there appeared to be substantive gains in employee job satisfaction. This result indicated that while satisfaction is influenced by challenge-related stressors, as suggested in the stress literature, the relationship is shaped both by individual experiences at work and institutional differences. It is intriguing that this gain in satisfaction was not evident among employees in SOEs who reported high involvement and high challenge stress.

Nevertheless, our findings point to the importance of organisational ownership in influencing work dynamics which may affect the type of stressors to which an individual is exposed. The results indicate that while both Chinese SOEs and FIEs in the retail industry face similar market pressures, their embedded institutional elements greatly influence organisational strategies and practices and lead to different individual outcomes. Our results highlight the need for further research to help understand ownership as a contextual factor that influences the effect of organisational practices and the work environment upon individual work-related outcomes.

Empirically, our study contributes to the JDC literature in two key ways. First, addressing the limited and inconsistent empirical evidence for the hypothesised two-way interactive effects between demands and control upon job satisfaction (Brown et al., 2014; Häusser et al., 2010), we provide further empirical evidence to help understand this understudied interaction. Surprisingly, while both employee involvement and challenge-related stressors were found to strongly and positively influence perceptions of job satisfaction, the hypothesised two-way interaction (Hypothesis 2) did not further strengthen the positive relationship between perceived 
challenge-related stressors and job satisfaction. Nevertheless, this is largely consistent with previous literature which finds that despite the strong main effects of job demands and control, the hypothesised interactions are often not supported (e.g., Beehr et al., 2001; McClenahan et al., 2007). Second, our study of Chinese retail employees adds value to this general prediction by providing evidence that these effects occur through both direct and moderating linkages. In terms of direct effects, our results showed challenge-related stressors to be significantly and positively related to job satisfaction. This positive relationship confirms that existing challengerelated stressors-job satisfaction findings, derived largely from Western contexts, can be replicated in a substantively different institutional and cultural environment - the Chinese retail industry.

\section{Practical implications}

This study also has practical implications for human resource professionals. First, in order to promote employee well-being, managers in both ownership types should consider how to increase employees’ job satisfaction by creating a more participative working atmosphere and endeavouring to ensure that employees feel more challengingly motivated at work, since these aspects related significantly to employees' reported job satisfaction. For example, if the interactive hypothesis is valid, job control should be increased to improve job satisfaction, whereas demands do not necessarily need to be reduced. In contrast, increasing job control would not have the same effect if job demands and control were only connected additively. In this case, job satisfaction might be increased by measures implementing job control, but the change would depend upon the level of control relative to job demands. Second, an encouraging message for FIEs is that HRM practices developed and already proven successful in their home countries might be a source of competitive advantage in the Chinese context. Moreover, our findings also suggest that it may be difficult for local SOEs to mimic successfully the HRM 
practices of foreign firms. Simply copying FIEs employee involvement practices, for instance, might bring few appreciable benefits to SOEs unless the broader contextual environment that underpins their positive role in FIEs is better understood and other relevant dimensions integrated into these local firms. Thus, in the area of stress management, attention should be focused not only on different stressors, but also various contextual factors which may affect the type of stressors to which an individual is exposed when HR managers conduct stress intervention or training programmes in these two different ownership types.

\section{Limitations}

Our study has certain limitations. Firstly, the cross-sectional nature of the data does not allow a clear inference of a cause-effect relationship. Secondly, our research relied on employees’ self-reports of the variables in our analyses. Generally, it is desirable to obtain independent or objective measures of the dependent variables. However, lack of such independence is not an overwhelming problem in this case, given that we were assessing the strength of employees' perceptions of the extent to which they feel satisfied with their job and how this is moderated by objective features of the context within which work is being performed. Moreover, many employee attitudinal outcomes would not readily be available to an alternative rating source (Spector, 2006, p. 229). Nevertheless, single source data does raise concern about CMB (Podsakoff et al., 2012). We encourage future researchers to consider separating the measurement of independent and dependent variables while concurrently using different raters of the independent and dependent variables. Thirdly, we consider this current paper to be an exploratory investigation into the impact of ownership. We encourage further research to capture more fine-grained situation-specific factors and their impact on the relationships we tested. Fourthly, the average age of employees included in this study is relatively young. That said, it is notable that retail employees generally "are typically young and inexperienced 
workers” (Ackfeldt \& Coote, 2005, p. 151), and this is paralleled in other studies using Chinese retail samples (e.g., Gamble, 2008; Huang \& Gamble, 2011, 2015; Lam, Walter, \& Ouyang, 2014; Leung, 1997). In addition, those aged 25 to 35 are the main age group targeted by FIEs in China (Financial Times, 2006). Moreover, FIEs face particular difficulties in retaining staff in this age group. Understanding better the factors that motivate and engender job satisfaction among such employees should be beneficial to HR managers. Finally, our research focussed on challenge rather than hindrance-related stressors. Although hindrance-related stressors have been found to have consistent, direct negative effects and an interactive effect with job control upon job satisfaction, little is known about whether these negative relationships still hold true when specific contextual factors are included, such as industry and organisational ownership. Thus, future research would benefit from including both challenge and hindrance-related stressors and assessing their differential effects.

\section{Future research}

Our findings indicate the significance of investigating the role of organisational ownership; they also highlight the need for further research to help understand ownership as a contextual factor that influences the effect of organisational practices and work environment upon individual work-related outcomes. Research on this topic could be carried out in other country contexts to assess the extent to which organisational ownership differences more generally affect work outcomes. Future research could disaggregate FIEs by nationality. Comparisons could also be made between SOEs in varying parts of China to examine the extent of regional differentiation. Another valuable agenda would be to conduct diachronic studies to enable analysis of the nature and direction of change over time. For instance, analysis could be carried out to examine the extent to which the differences we found between SOEs and FIEs persist. China's SOEs have not been static, they have undergone considerable reform over the past two decades (Ralston, Pounder, Lo, Wong, Egri, \& Stauffer, 2006), and have gradually adopted 
more Western-style HRM practices (Zhu et al., 2005). Studies to investigate POEs, an increasingly prevalent enterprise form in China, could compare them with both FIEs and SOEs. Research has indicated that the values of hierarchy and paternalistic leadership found in SOEs, also predominate in POEs. These features could be expected to raise barriers to employee involvement in the workplace (Huang \& Gamble, 2011; Lu et al., 2009). We utilised organisational ownership as a broad "catch-all" category. Future research needs to drill deeper into this category to better understand the discrete factors at work; these might include features such as corporate culture or specific organisational practices. For instance, it may be that compared with SOEs, FIEs offer greater rewards to those who demonstrate a capacity for greater involvement and who respond positively to challenge-related stressors.

More broadly, future research could investigate the individual values held by workers in greater depth. It would be valuable to assess the extent to which different organisational types attract employees who already hold different values, and the degree to which these are malleable in the employment context. In China, for instance, FIEs might attract and recruit more recruits who are predisposed to appreciate the possibilities for greater involvement and a challenging work environment. It would also be worthwhile to analyse different categories of employee separately, for example, managerial and shopfloor staff, and employees of different age and gender. Researchers could also investigate the impact of different forms of employee involvement. According to the model developed by Lavelle et al. (2010), employee involvement in the firms we examined ranged from weak/low to low/moderate. That is, it focused largely upon consultation and information sharing rather than "stronger" forms of involvement. Future research could compare our findings with those from firms that engage in "strong” forms of employee involvement to ascertain whether the relationships we report also hold true or, indeed, are stronger.

\section{Conclusion}


The retail sector contributes significantly to many economies' gross domestic product; however, it is often neglected in the HRM literature. This study enriches the literature by using a sample drawn from a transitional, developing country. Our results regarding the job stress-satisfaction relationship in China's retail industry parallel those derived from Western contexts. Our study adds value to this general prediction by providing evidence that these effects occur through both direct linkages and via moderating linkages. In terms of direct effects, our results showed challenge-related stressors to be significantly and positively related to job satisfaction. Our study also contributes to the literature by comparing the influence of challenge-related stressors in firms of different ownership (FIEs and SOEs) in this industry. We consider this is significant given that different organisational ownerships' embedded institutional elements influence organisational strategies and practices, which might affect the type of stressors to which an individual is exposed, and in turn lead to different individual outcomes. Existing studies have demonstrated the moderating effect of ownership on the HRM-firm performance relationship in the Chinese context (Law et al., 2003; Ng \& Siu, 2004; Ngo et al., 2008; Wei \& Lau, 2008). Providing further support to the importance of ownership, we found that organisational ownership can significantly impact on the stress-job satisfaction relationship. This dimension requires consideration both as a potentially important variable in research on HR practices; it also needs to be disaggregated and its key components distinguished and analysed separately. Lastly, our findings suggest a way in which research on HRM can contribute to organisational theory. Xu et al. (2014, p. 521) observe that "new organisational forms require recognition and legitimation to survive and proliferate”, in particular when they constitute "adversarial” or “opposing ideologies”, as in the case of FIEs and SOEs in China. The positive HRM outcomes presented by the FIEs in our study might be a significant way in which they attain legitimacy, thereby helping to ensure their continued existence and proliferation. 


\section{References}

Ackfeldt, A. L., \& Coote, L. V. (2005). A study of organizational citizenship behaviors in a retail setting. Journal of Business Research, 58, 151-159. doi: 10.1016/S01482963(03)00110-3

Aiken, L. S., \& West, S. G. (1991). Multiple regression: Testing and interpreting interactions. London: Sage Publications.

Arnold, T., Flaherty, K. E., Voss, K. E., \& Mowen, J. C. (2009). Role stressors and retail performance: the role of perceived competitive climate. Journal of Retailing, 85, 194-205. doi: 10.1016/j.jretai.2009.02.002

Beehr, T. A., Glaser, K. M., Canali, K. G., \& Wallwey, D. A. (2001). Back to basics: Reexamination of Demand-Control Theory of occupational stress. Work \& Stress, 15, 115-130. doi: 10.1080/02678370110067002

Bentler, P. M. (1990). Comparative fit indexes in structural models. Psychological Bulletin, 107, 238-246. doi: 10.1037/0033-2909.107.2.238

Boswell, W. R., Olson-Buchanan, J. B., \& LePine, M. A. (2004). Relations between stress and work outcomes: The role of felt challenge, job control, and psychological strain. Journal of Vocational Behavior, 64, 165-181. doi: 10.1016/S0001-8791(03)00049-6

Boxall, P., \& Macky, K. (2014). High-involvement work processes, work intensification and employee well-being. Work, Employment \& Society, 28, 963-984. doi: $10.1177 / 0950017013512714$

Bozkurt, O., \& Grugulis, I. (2011). Introduction: why retail work demands a closer look. In O. Bozkurt \& I. Grugulis (Eds.), Retail work (critical perspectives on work and employment) (pp. 1-21). Basingstoke: Palgrave Macmillan.

Braun, W. H., \& Warner, M. (2002). Strategic human resource management in Western multinationals in China: The differentiation of practices across different ownership forms. Personnel Review, 31, 553-579. doi: 10.1108/00483480210438762 
Broadbridge, A. (2002). Retail managers: their work stressors and coping strategies. Journal of Retailing and Consumer Services, 9, 173-183. doi: 10.1016/S0969-6989(01)00020-0

Brown, M., Pitt-Catsouphes, M., McNamara, T. K., \& Besen, E. (2014). Returning to the workforce after retiring: A job demands, job control, social support perspective on job satisfaction. The International Journal of Human Resource Management, 25, 3113-3133. doi: 10.1080/09585192.2014.919951

Carr, M. D., \& Mellizo, P. (2013). The relative effect of voice, autonomy, and the wage on satisfaction with work. The International Journal of Human Resource Management, 24, 1186-1201. doi: 10.1080/09585192.2012.706818

Cavanaugh, M. A., Boswell, W. R., Roehling, M. V., \& Boudreau, J. W. (2000). An empirical examination of self-reported work stress among US managers. Journal of Applied Psychology, 85, 65-74. doi: 10.1037/0021-9010.85.1.65

Chiang, F. F., Birtch, T. A., \& Kwan, H. K. (2010). The moderating roles of job control and work-life balance practices on employee stress in the hotel and catering industry. International Journal of Hospitality Management, 29, 25-32. doi: 10.1016/j.ijhm.2009.04.005

Coelho, F., Augusto, M., \& Lages, L. F. (2011). Contextual factors and the creativity of frontline employees: The mediating effects of role stress and intrinsic motivation. Journal of Retailing, 87, 31-45. doi: 10.1016/j.jretai.2010.11.004

Conger, J. A., Kanungo, R. N., \& Menon, S. T. (2000). Charismatic leadership and follower effects. Journal of Organizational Behavior, 21, 747-767. doi: 10.1002/10991379(200011)21:7<747::AID-JOB46>3.0.CO;2-J

Cox, A., Zagelmeyer, S., \& Marchington, M. (2006). Embedding employee involvement and participation at work. Human Resource Management Journal, 16, 250-267. doi: 10.1111/j.1748-8583.2006.00017.x 
Dawson, J. F., \& Richter, A. W. (2006). Probing three-way interactions in moderated multiple regression: Development and application of a slope difference test. Journal of Applied Psychology, 91, 917-926. doi: 10.1037/0021-9010.91.4.917

De Lange, A. H., Taris, T. W., Kompier, M. A., Houtman, I. L., \& Bongers, P. M. (2004). The relationships between work characteristics and mental health: Examining normal, reversed and reciprocal relationships in a 4-wave study. Work \& Stress, 18, 149-166. doi: $10.1080 / 02678370412331270860$

De Witte, H., Verhofstadt, E., \& Omey, E. (2007). Testing Karasek's learning and strain hypotheses on young workers in their first job. Work \& Stress, 21, 131-141. doi: $10.1080 / 02678370701405866$

Doest, L., \& Jonge, J. (2006). Testing causal models of job characteristics and employee wellbeing: A replication study using cross-lagged structural equation modelling. Journal of Occupational and Organizational Psychology, 79, 499-507. doi: 10.1348/096317905X55271

Financial Times (2006). Multinationals in China struggle to keep staff, 1 September.

Gamble, J. (2003). Transferring human resource practices from the United Kingdom to China: The limits and potential for convergence. The International Journal of Human Resource Management, 14, 369-387. doi: 10.1080/0958519022000031807

Gamble, J. (2006). Introducing Western-style HRM practices to China: Shopfloor perceptions in a British multinational. Journal of World Business, 41, 328-343. doi: 10.1016/j.jwb.2006.08.002

Gamble, J. (2010). Transferring organizational practices and the dynamics of hybridization: Japanese retail multinationals in China. Journal of Management Studies, 47, 705-732. doi: 10.1111/j.1467-6486.2009.00876.x

Gamble, J. (2011). Multinational retailers and consumers in China: transferring organizational 
practices from the United Kingdom and Japan. London: Palgrave.

Gamble, J., \& Huang, Q. H. (2008). Organisational commitment of Chinese employees in foreign-invested firms. The International Journal of Human Resource Management, 19, 896-915. doi: 10.1080/09585190801993893

Gamble, J., \& Huang, Q. H. (2009). The transfer of organizational practices: A diachronic perspective from China. The International Journal of Human Resource Management, 20, 1683-1703. doi: 10.1080/09585190903087032

Grandey, A. A. (2003). When "the show must go on": Surface acting and deep acting as determinants of emotional exhaustion and peer-rated service delivery. Academy of Management Journal, 46, 86-96. doi: 10.2307/30040678

Häusser, J. A., Mojzisch, A., Niesel, M., \& Schulz-Hardt, S. (2010). Ten years on: A review of recent research on the Job Demand-Control (-Support) model and psychological well-being. Work \& Stress, 24, 1-35. doi: 10.1080/02678371003683747

Heskett, J. L., Sasser, W. E., \& Schlesinger, L. A. (1997). The service profit chain. New York: Free Press.

Hofstede, G. (2001). Culture's consequences: comparing values, behaviors, institutions, and organizations across nations (2nd ed.). Thousand Oaks, CA: Sage.

Holland, P., Pyman, A., Cooper, B. K., \& Teicher, J. (2011). Employee voice and job satisfaction in Australia: The centrality of direct voice. Human Resource Management, 50, 95-111. doi: 10.1002/hrm.20406

Hu, L. T., \& Bentler, P. M. (1999). Cutoff criteria for fit indexes in covariance structure analysis: Conventional criteria versus new alternatives. Structural Equation Modeling, 6, 1-55. doi: $10.1080 / 10705519909540118$

Huang, Q. H., \& Gamble, J. (2011). Informal institutional constraints and their impact on HRM and employee satisfaction: Evidence from China's retail sector. The International Journal of 
Human Resource Management, 22, 3168-3186. doi: 10.1080/09585192.2011.560879

Huang, Q. H., \& Gamble, J. (2015). Social expectations, gender and job satisfaction: Front-line employees in China's retail sector. Human Resource Management Journal, 25, 331-347. doi: 10.1111/1748-8583.12066

Jin, J. F., Fosh, P., \& Chen, C. C. (2012). When East meets West: Interaction effects of organisational ownership structure, gender and (un) met expectations on workers' attitudes in China. The International Journal of Human Resource Management, 23, 18-34. doi: $10.1080 / 09585192.2011 .631838$

Karasek, R. A. (1979). Job demands, job decision latitude, and mental strain: Implications for job redesign. Administrative Science Quarterly, 24, 285-308. doi: 10.2307/2392498

Karasek, R. T., \& Theorell, T. (1990). Healthy work-stress, productivity and the reconstruction of working life. New York: Basic books.

Katsikea, E., Theodosiou, M., \& Morgan, R. E. (2015). Why people quit: Explaining employee turnover intentions among export sales managers. International Business Review, 24, 367379. doi: 10.1016/j.ibusrev.2014.08.009

Kim, S., Wright, P. M., \& Su, Z. (2010). Human resource management and firm performance in China: A critical review. Asia Pacific Journal of Human Resources, 48, 58-85. doi: $10.1177 / 1038411109356496$

Lam, C. K., Walter, F., \& Ouyang, K. (2014). Display rule perceptions and job performance in a Chinese retail firm: The moderating role of employees’ affect at work. Asia Pacific Journal of Management, 31, 575-597. doi: 10.1007/s10490-013-9348-6

Lashley, C. (2001). Empowerment: HR strategies for service excellence. London: Routledge.

Lavelle, J., Gunnigle, P., \& McDonnell, A. (2010). Patterning employee voice in multinational companies. Human Relations, 63, 395-418. doi: 10.1177/0018726709348935

Law, K. S., Tse, D., \& Zhou, N. (2003). Does human resource management matter in a 
transitional economy? China as an example. Journal of International Business Studies, 34, 255-265. doi: 10.1057/palgrave.jibs.8400026

LePine, J. A., Podsakoff, N. P., \& LePine, M. A. (2005). A meta-analytic test of the challenge stressor-hindrance stressor framework: An explanation for inconsistent relationships among stressors and performance, Academy of Management Journal, 48, 764-775. doi: 10.5465/AMJ.2005.18803921

Leung, K. (1997). Relationships among satisfaction, commitment, and performance: A grouplevel analysis. Applied Psychology, 46, 199-205. doi: 10.1111/j.1464-0597.1997.tb01224.x

Lindell, M. K., \& Whitney, D. J. (2001). Accounting for common method variance in crosssectional research designs. Journal of Applied Psychology, 86, 114-121. doi: 10.1037/00219010.86.1.114

Lu, C. Q., Siu, O. L., Au, W. T., \& Leung, S. S. (2009). Managers’ occupational stress in stateowned and private enterprises in the People's Republic of China. The International Journal of Human Resource Management, 20, 1670-1682. doi: 10.1080/09585190903087024

Mackie, K. S., Holahan, C. K., \& Gottlieb, N. H. (2001). Employee involvement management practices, work stress, and depression in employees of a human services residential care facility. Human Relations, 54, 1065-1092. doi: 10.1177/0018726701548004

Macky, K., \& Boxall, P. (2008). High-involvement work processes, work intensification and employee well-being: A study of New Zealand worker experiences. Asia Pacific Journal of Human Resources, 46, 38-55. doi: 10.1177/1038411107086542.

McClenahan, C. A., Giles, M. L., \& Mallett, J. (2007). The importance of context specificity in work stress research: A test of the Demand-Control-Support model in academics. Work \& Stress, 21, 85-95. doi: 10.1080/02678370701264552

Mullen, M. R. (1995). Diagnosing measurement equivalence in cross-national research. Journal of International Business Studies, 26, 573-596. doi: Retrieved from 
http://www.jstor.org/stable/155562

Muthén, L. K., \& Muthén, B. O. (2007). Mplus user’s guide. Los Angeles, CA: Muthén \& Muthén.

Ng, Y. C., \& Siu, N. Y. (2004). Training and enterprise performance in transition: Evidence from China. The International Journal of Human Resource Management, 15, 878-894. doi: $10.1080 / 0958519042000192997$

Ngo, H. Y., Lau, C. M., \& Foley, S. (2008). Strategic human resource management, firm performance, and employee relations climate in China. Human Resource Management, 47, 73-90. doi: 10.1002/hrm.20198

Pearsall, M. J., Ellis, A. P., \& Stein, J. H. (2009). Coping with challenge and hindrance stressors in teams: Behavioral, cognitive, and affective outcomes. Organizational Behavior and Human Decision Processes, 109, 18-28. doi: 10.1016/j.obhdp.2009.02.002

Peng, M. W. (2003). Institutional transitions and strategic choices. Academy of Management Review, 28, 275-296. doi: 10.5465/AMR.2003.9416341

Peng, M. W., Tan, J., \& Tong, T. W. (2004). Ownership types and strategic groups in an emerging economy. Journal of Management Studies, 41, 1105-1129. doi: 10.1111/j.14676486.2004.00468.x

Podsakoff, N. P., LePine, J. A., \& LePine, M. A. (2007). Differential challenge stressorhindrance stressor relationships with job attitudes, turnover intentions, turnover, and withdrawal behavior: A meta-analysis. Journal of Applied Psychology, 92, 438-454. doi: 10.1037/0021-9010.92.2.438

Podsakoff, P. M., MacKenzie, S. B., \& Podsakoff, N. P. (2012). Sources of method bias in social science research and recommendations on how to control it. Annual Review of Psychology, 63, 539-569. doi: 10.1146/annurev-psych-120710-100452

Ralston, D. A., Pounder, J., Lo, C. W. H., Wong, Y. Y., Egri, C. P., \& Stauffer, J. (2006). 
Stability and change in managerial work values: A longitudinal study of China, Hong Kong, and the US. Management and Organization Review, 2, 67-94. doi: 10.1111/j.17408784.2006.00031.x

Spector, P. E. (2006). Method variance in organizational research truth or urban legend? Organizational Research Methods, 9, 221-232. doi: 10.1177/1094428105284955

Taras, V., Kirkman, B. L., \& Steel, P. (2010). Examining the impact of Culture’s Consequences: A three-decade, multi-level, meta-analytic review of Hofstede’s cultural value dimensions. Journal of Applied Psychology, 95, 405-439. doi: 10.1037/a0018938

Vandenberghe, C., Panaccio, A., Bentein, K., Mignonac, K., \& Roussel, P. (2011). Assessing longitudinal change of and dynamic relationships among role stressors, job attitudes, turnover intention, and well-being in neophyte newcomers. Journal of Organizational Behavior, 32, 652-671. doi: 10.1002/job.732

Wang, X. H. (2008). Analyzing work attitudes of Chinese employees: A comparison between state-owned and privately-owned enterprises in China. Chinese Management Studies, 2, 215-228. doi: 10.1108/17506140810895906

Wang, Y. Y. (2004). Observations on the organizational commitment of Chinese employees: Comparative studies of state-owned enterprises and foreign-invested enterprises. The International Journal of Human Resource Management, 15, 649-669. doi: $10.1080 / 0958519042000192889$

Warr, P. B. (2007). Work, happiness, and unhappiness. London: Taylor \& Francis.

Webster, J. R., Beehr, T. A., \& Christiansen, N. D. (2010). Toward a better understanding of the effects of hindrance and challenge stressors on work behavior. Journal of Vocational Behavior, 76, 68-77. doi: 10.1016/j.jvb.2009.06.012

Webster, J. R., Beehr, T. A., \& Love, K. (2011). Extending the challenge-hindrance model of occupational stress: The role of appraisal. Journal of Vocational Behavior, 79, 505-516. doi: 
10.1016/j.jvb.2011.02.001

Wei, L. Q., \& Lau, C. M. (2008). The impact of market orientation and strategic HRM on firm performance: The case of Chinese enterprises. Journal of International Business Studies, 39, 980-995. doi: 10.1057/palgrave.jibs.8400395

Widerszal-Bazyl, M., Cooper, C. L., Sparks, K., \& Spector, P. E. (2000). Managerial stress in private and state organisations in Poland. Stress and Health, 16, 299-314. doi: Retrieved from http://www.ingentaconnect.com/content/jws/smi/2000/00000016/00000005/art00874

Wood, S. (2008). Job characteristics, employee voice and well-being in Britain. Industrial Relations Journal, 39, 153-168. doi: 10.1111/j.1468-2338.2007.00482.x

Wood, S., \& de Menezes, L. M. (2011). High involvement management, high-performance work systems and well-being. The International Journal of Human Resource Management, 22, 1586-1610. doi: 10.1080/09585192.2011.561967

Wood, S., Van Veldhoven, M., Croon, M., \& de Menezes, L. M. (2012). Enriched job design, high involvement management and organizational performance: The mediating roles of job satisfaction and well-being. Human Relations, 65, 419-445. doi: $10.1177 / 0018726711432476$

Xu, D., Lu, J. W., \& Gu, Q. (2014). Organizational forms and multi-population dynamics: Economic transition in China. Administrative Science Quarterly, 59, 3, 517-547. doi: $10.1177 / 0001839214541866$

Zhu, C. J., Cooper, B., De Cieri, H., \& Dowling, P. J. (2005). A problematic transition to a strategic role: Human resource management in industrial enterprises in China. The International Journal of Human Resource Management, 16, 513-531. doi: $10.1080 / 09585190500051514$ 
Table 1.

Sample characteristics by organisational ownership type

\begin{tabular}{lllllll}
\hline Demographic characteristics & FIEs & & SOEs & & Total \\
\hline \multirow{2}{*}{ Gender } & Male & 403 & $47.2 \%$ & 342 & $35.1 \%$ & 745 \\
& Female & 451 & $52.8 \%$ & 633 & $64.9 \%$ & 1084 \\
\hline \multirow{2}{*}{ Job-level } & Non-managerial staff & 694 & $83.2 \%$ & 670 & $70.0 \%$ & 1364 \\
& Managerial staff & 140 & 16.8 & 287 & $30.0 \%$ & 427 \\
\hline \multirow{3}{*}{ Education } & High school and below & 605 & $72.0 \%$ & 456 & $50.4 \%$ & 1061 \\
& College & 172 & $20.5 \%$ & 269 & $29.8 \%$ & 441 \\
& University and above & 63 & $7.5 \%$ & 179 & $19.8 \%$ & 242 \\
\hline \multirow{5}{*}{ Age } & Less than 22 years old & 110 & $13.0 \%$ & 78 & $8.0 \%$ & 188 \\
& 22-27 years old & 412 & $48.6 \%$ & 560 & $57.6 \%$ & 972 \\
& 28-33 years old & 230 & $27.1 \%$ & 242 & $24.9 \%$ & 472 \\
& 34-45 years old & 88 & $10.4 \%$ & 80 & $8.2 \%$ & 168 \\
& 46 and above & 8 & $0.9 \%$ & 13 & $1.3 \%$ & 21 \\
\hline \multirow{5}{*}{ Tenure } & Less than 1 year & 334 & $38.9 \%$ & 278 & $28.4 \%$ & 612 \\
& 1-2 years & 195 & $22.7 \%$ & 254 & $25.9 \%$ & 449 \\
& 3-4 years & 171 & $19.9 \%$ & 160 & $16.3 \%$ & 331 \\
& 5 years and above & 155 & $18.0 \%$ & 283 & $28.9 \%$ & 438 \\
\hline
\end{tabular}

SOEs = State-owned enterprises, FIEs $=$ Foreign-invested enterprises 
Table 2.

Descriptive statistics and inter-correlations for study variables

\begin{tabular}{|c|c|c|c|c|c|c|c|c|c|c|}
\hline Variables & $\mathrm{M}$ & SD & 1 & 2 & 3 & 4 & 5 & 6 & 7 & 8 \\
\hline 1. Gender ${ }^{\mathrm{a}}$ & .61 & .49 & & & & & & & & \\
\hline 2. Age ${ }^{b}$ & .38 & .48 & -.02 & & & & & & & \\
\hline 3. Education ${ }^{\mathrm{c}}$ & .39 & .48 & -.04 & $-.06 * *$ & & & & & & \\
\hline 4. Tenure $^{\mathrm{d}}$ & .43 & .50 & $.11^{* *}$ & $.21 * *$ & -.01 & & & & & \\
\hline 5. Job level ${ }^{\mathrm{e}}$ & .24 & .43 & -.02 & $.09 * *$ & $.19 * *$ & $.28 * *$ & & & & \\
\hline 6. Challenge-related stressors & 3.69 & .63 & $-.06 * *$ & $.06 * *$ & -.03 & $.06 * *$ & $.13 * *$ & & & \\
\hline 7. Employee involvement & 2.58 & .69 & $-.12 * *$ & .03 & $-.07 * *$ & .03 & $.16^{* *}$ & $.23^{*}$ & & \\
\hline 8. Ownership type & .47 & .50 & $-.12 * *$ & .03 & $-.22 * *$ & $-.07 * *$ & $-.16^{* *}$ & $.06 * *$ & $.16^{* *}$ & \\
\hline 9. Job satisfaction & 3.15 & .49 & $-.09 * *$ & $.04^{+}$ & $-.05 *$ & -.03 & $.14^{* *}$ & $.21 * *$ & $.40 * *$ & $.05 *$ \\
\hline
\end{tabular}

Notes: ${ }^{\text {a }} 1=$ Female; ${ }^{\text {b }} 1=$ Aged 28 and above; ${ }^{\mathrm{c}} 1=$ College and above; ${ }^{\mathrm{d}} 1=2$ years and above; ${ }^{\mathrm{e}} 1=$ Managerial staff

Statistically significant at ${ }^{+} \mathrm{p}<.10,{ }^{*} p<.05,{ }^{* *} p<.01$ 
Table 3.

Mean differences for study variables by organisational ownership type

\begin{tabular}{llllll}
\hline \multirow{2}{*}{ Variables } & \multicolumn{2}{l}{ SOEs $(\mathrm{n}=980)$} & \multicolumn{2}{l}{ FIEs $(\mathrm{n}=859)$} & \multirow{2}{*}{ F-value } \\
\cline { 2 - 5 } & Mean & SD & Mean & SD & \\
\hline Challenge-related stressors & 3.65 & .65 & 3.73 & .62 & $6.73^{* *}$ \\
Employee involvement & 3.13 & .50 & 3.18 & .48 & $4.44^{*}$ \\
Job satisfaction & 2.48 & .72 & 2.70 & .66 & $47.10^{* * *}$ \\
\hline
\end{tabular}

Note: Statistically significant at $* p<0.05,{ }^{* *} p<0.01,{ }^{* * *} p<0.001$

SOEs $=$ State-owned enterprises, FIEs $=$ Foreign-invested enterprises 
Table 4.

Results of hierarchical moderated regression analyses for job satisfaction

\begin{tabular}{|c|c|c|c|c|}
\hline \multirow{2}{*}{ Variables } & \multicolumn{4}{|c|}{ Job Satisfaction } \\
\hline & Model 1 & Model 2 & Model 3 & Model 4 \\
\hline \multicolumn{5}{|l|}{ Step 1 (control variables) } \\
\hline Female & $-.10^{* * *}$ & $-.04^{+}$ & $-.04^{+}$ & $-.04^{+}$ \\
\hline Managerial staff & $.19 * * *$ & $.09 * *$ & $.09 * *$ & $.09 * *$ \\
\hline \multicolumn{5}{|l|}{ Age group (ref: less than 22 years } \\
\hline \multicolumn{5}{|l|}{ old) } \\
\hline $22-27$ & -.02 & -.02 & -.02 & -.02 \\
\hline $28-33$ & .01 & -.01 & -.01 & -.01 \\
\hline $34-45$ & .08 & .05 & .05 & .05 \\
\hline 46 and above & .45 & .49 & .50 & .53 \\
\hline \multicolumn{5}{|l|}{$\begin{array}{l}\text { Education (ref: high school and } \\
\text { below) }\end{array}$} \\
\hline College & $-.05^{+}$ & -.02 & -.02 & -.02 \\
\hline University and above & $-.14^{* * *}$ & $-.06^{+}$ & $-.06^{+}$ & $-.06^{+}$ \\
\hline \multicolumn{5}{|l|}{ Tenure (ref: Less than 1 year) } \\
\hline 1-2 years & -.04 & -.01 & -.01 & -.01 \\
\hline 3-4 years & $-.08 *$ & $-.06^{+}$ & $-.06^{+}$ & $-.06^{+}$ \\
\hline 5 years and above & $-.12 * *$ & $-.08 *$ & $-.08 *$ & $-.08 *$ \\
\hline \multicolumn{5}{|l|}{ Step 2 (main predictors, H1) } \\
\hline Challenge-related stressors & & $.09 * * *$ & $.09 * * *$ & $.08 * * *$ \\
\hline Employee involvement & & $.26 * * *$ & $.26^{* * *}$ & $.26 * * *$ \\
\hline Ownership & & -.01 & .01 & -.01 \\
\hline \multicolumn{5}{|l|}{ Step 3 (two-way interaction, H2) } \\
\hline Challenge-related stressor $\mathbf{x}$ & & & .01 & -.03 \\
\hline \multicolumn{5}{|c|}{ Employee involvement } \\
\hline \multicolumn{5}{|c|}{ Step 4 (three-way interaction, H3) } \\
\hline Challenge-related stressor $\mathbf{x}$ & & & & $.09 *$ \\
\hline \multicolumn{5}{|l|}{ Employee involvement $\mathbf{x}$} \\
\hline \multicolumn{5}{|l|}{ Ownership } \\
\hline$R^{2}$ & .06 & .21 & .21 & .21 \\
\hline $\operatorname{Adj} R^{2}$ & .05 & .20 & .20 & .20 \\
\hline$\Delta R^{2}$ & & .15 & $<.01$ & .01 \\
\hline F-value & $8.06 * * *$ & $26.80 * * *$ & $25.00 * * *$ & $23.67 * * *$ \\
\hline$\Delta \mathrm{F}$ & & $90.06 * * *$ & .06 & 3.22* \\
\hline
\end{tabular}


Table 5.

Slope differences for three-way interaction: Employee involvement, challenge-related stressors and organisational ownership

\begin{tabular}{|c|c|c|}
\hline Pair of slopes & $\begin{array}{l}\text { t-value for slope } \\
\text { difference }\end{array}$ & $\begin{array}{l}\text { p-value for slope } \\
\text { difference }\end{array}$ \\
\hline (1) and (2) & 3.004 & .003 \\
\hline (1) and (3) & 3.041 & .002 \\
\hline (1) and (4) & 2.817 & .005 \\
\hline (2) and (3) & -1.207 & .227 \\
\hline (2) and (4) & -.826 & .409 \\
\hline (3) and (4) & -.158 & .874 \\
\hline
\end{tabular}


Figure 1.

Three-way interaction with job satisfaction as dependent variable

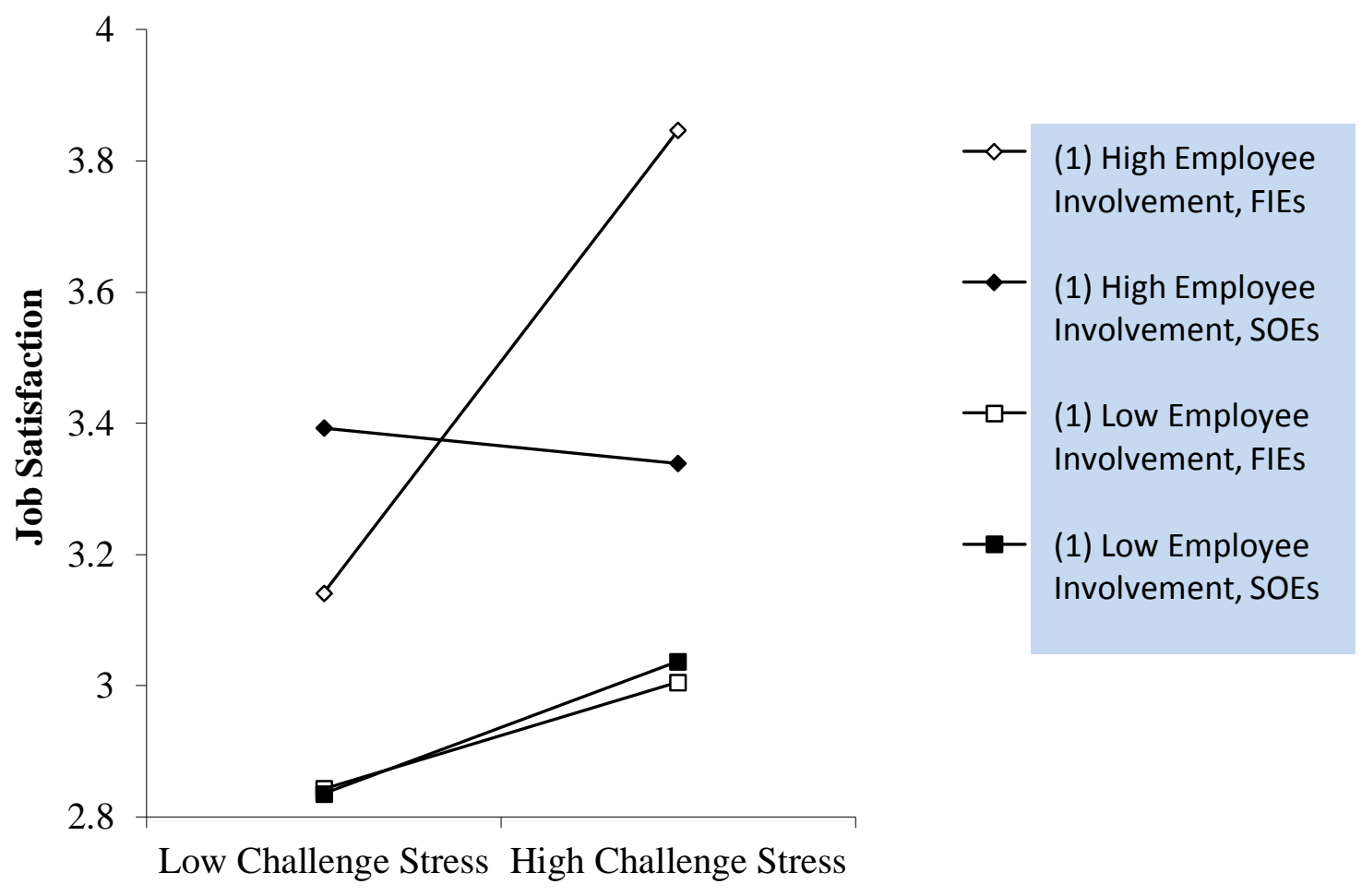


Page 41 of 41 